\title{
Education's Role in Maintaining the Individual's Status
}

\author{
By Wilma T. Donahue
}

\begin{abstract}
$\mathrm{A}$ GING is a process of change, and can be fully understood only when it is viewed in the perspective of a continuous life flow from conception to death. The differentiation and maturation of cellular material and its involution and senescence constitute the continuously changing biological substructure of the aging organism. Each change in function is conditioned by concomitant or preceding biological circumstances and by environmental stress to which the aging individual is exposed. The concept of the individual
\end{abstract} as a functional but changing whole moving through a dynamic life space has been accepted in the study and treatment of children; it has not yet been fully comprehended as including the total life span.

The period of later maturity has been traditionally regarded as static, as a time when the individual's development has been halted and his potentialities dissipated by the blight of age, during which he can only await his ultimate dismissal from life. Fortunately, there is a growing awareness that age in itself need not impale the individual and transform his life from a state of useful participation to one of doddering retirement. Resources for personal development are lodged within the individual throughout all his years. Educators have assumed responsibility for stimulating, developing, and preparing youth for the roles of early adulthood; their responsibility for rendering a corresponding service to the older adult for his role in later life appears obvious.

\section{Functions of Education for the Older Adult}

The major function of education for older adults is to help them to continue the exploration of their potentialities, and to assist them in preserving their integration in society. To achieve such a broad objective, education must design a fourfold program. First, it must aid in the adjustment of the individual to the personal and social changes accompanying aging by providing information necessary to achieve lifelong adjustment. Second, it must promote the adjustment of society to its aging population by helping to create appropriate attitudes and by encouraging the development of opportunities for the continued use of the talents and skills of older citizens. Third, it must train personnel to serve older people by establishing courses of study, programs of field practice, and in-service training in gerontology. Finally, it must promote research for the development of a body of knowledge about aging and its implications for individual and social practice.

Although there is admittedly much to be learned, gerontologists already have sufficient information, if they were to apply it, to improve markedly the economic status, the health, and the emotional welfare of aging adults, and to assist communities in developing patterns providing for role maintenance with age. This information must be made available to the aging and their society through broad educational chan- 
nels. The programs currently in progress and others which are under consideration represent important advances in this new phase of adult education. Before reporting upon these, however, it is in order to discuss some of the considerations common to all approaches of education for the older adult.

\section{Problems and Needs}

Modern education for youth has attempted to identify the critical life issues and basic needs with which the developing individual must be equipped to deal. Through the regular curriculum, it has then set about to provide training and skill for making the necessary adjustments. This approach has not been extended to form the basis of adult education. As Thomas Van Sant has pointed out, "education for adults has been and to a large extent still exists as a second chance for them to pick up things they missed for good, bad or indifferent reasons when they were children, teen-agers or young adults." 1 More realistic and pertinent programs of education for all adults will result when their social, personal, and economic needs are analyzed, with these analyses used as a basis for designing programs which will help them in finding solutions and making adjustments throughout life.

\section{Reaching the older adult}

A primary problem encountered in implementing the ideal of lifelong learning is that of reaching the older adult. Those individuals who are now old have been exposed only casually to adult education. They suffer from fears generated from knowledge that they have experienced both physical

1 Thomas A. Van Sant, "Responsibility of Education to the Older Adult," in Growing in the Older Years (W. Donahue and C. Tibbitts, Eds., Ann Arbor: University of Michigan Press, 1951), p. 120. and mental change, and that they do not measure up to the academic requirements set for their children and grandchildren. They are unaccustomed to entering into group learning experiences. They are aware that public attitudes condone, if not encourage, their acceptance of passive patterns of behavior or the pursuit of happiness through purely recreational activities. As a result of these factors, they have not demanded educational opportunity, and, in far too many instances, have ceased from intellectual exploration upon graduation from the "little red schoolhouse" or its more modern counterpart.

If the few statistics available concerning the age distribution of students enrolled in regular adult education classes are typical, it is clear that present programs are not attracting many older adults. Willis Reals reports that only 4 per cent of students enrolled in the evening classes at Washington University are over 50 years of age. ${ }^{2}$ In one city school, the mean age of students in the adult education program is 26 years, with only 5 per cent over 50 years of age. In classes specifically designed for but not restricted to older adults average ages are of course higher: 53 years at the University of Illinois, ${ }^{3}$ and 62 years at the University of Michigan. ${ }^{4}$

In recognition that, at least for the present, only a limited number of older persons are becoming involved in activities offered directly by the school, the New York State Education Depart-

2 Willis H. Reals, "The Place of the University in the Education of the Aging," paper read at Second International Gerontological Congress, St. Louis, September 1951.

${ }^{3}$ Robert Peterson, "University Extension Courses in Gerontology," Journal of Gerontology, Vol. 6 (1951), p. 40.

4 Wilma Donahue, "Age with a Future," in Social Work in the Current Scene 1950 (New York: Columbia University Press, 1950), p. 82. 
ment now provides aid to local school systems for the implementation of programs being offered by other agencies. Under this arrangement, the educator is enabled to serve groups which are well established (such as golden-age clubs), to co-operate with industries in developing educational programs for retirement, and to assist churches, clubs, private and public community agencies, libraries, and homes for the aged in providing educational services to old people.

\section{Learning and the older adult}

Basic to a program of education for the older adult is the assumption that people can continue to learn throughout life. It has been estimated that 70 per cent of our older people are still mentally alert and active. There is good reason to believe that the way to maintain this mental alertness of the aging is through continued intellectual activity, such as educational experiences provide. That educators have been laggard in offering programs for older adults may reflect a lack of awareness of the effectiveness of learning as an antidote to psychological aging. When both educators and the aging are convinced that the adjustment of older people can be greatly improved through educational channels, it is probable that many new developments will take place.

\section{Content}

No clear-cut roles have crystallized for the adult beyond retirement age. This fact creates a problem in designing educational programs for older adults, since the starting point for planning should be the actual needs of the people served. Adult educators are loath to undertake the development of programs, preferring to wait until the ultimate role of the older individual in society and his associated problems are more clearly defined.
Although research data relative to the most appropriate content of educational programs for older adults are not yet available, we do not have the pooled judgments of the eighty members of the Education Section of the First National Conference on Aging as to the most important areas to be included. Areas recommended included education for physical and mental health, family and group membership, economic security, vocational skills, leisure-time pursuits, social and civic responsibility, and religious experience. ${ }^{5}$ At the Governor's Conference on the Problems of the Aging held in Sacramento, California, in October 1951, a study group recommended that education center its function around economic problems, physical and mental health, and leisure-time interests. ${ }^{6}$ In Homer Kempfer's study of the needs of older people, guidance services are also included in the recommended content of educational programs. $^{?}$

It is appropriate with reference to content of educational offerings to point out the need for modification of existing curricula at the various school levels in order to provide an interpretation to all ages of the potentialities and roles of older people in contemporary life.

\section{Techniques and materials}

It is perhaps fortunate that uniformity does not exist in the techniques being employed in the various educational programs throughout the country,

${ }^{5}$ National Conference on Aging, Washington, D. C., 1950, Man and His Years (Raleigh, N. C.: Health Publications Institute, 1951), pp. 135-36.

${ }^{6}$ Background Material for the Governor's Conference on the Problems of the Aging (Sacramento, Calif.: Department of Social Welfare, 1951), p. 6.

${ }^{7}$ Homer Kempfer, Education for a Long and Useful Life, Office of Education Bulletin No. 6, 1950 (Washington, D. C.: Federal Security Agency), pp. 14-29. 
because we are yet at an experimental stage of development. Research has not been. done on such questions as whether older people learn better in mixed age groups or in peer groups, whether smaller assignments are indicated, whether more time should be allowed for discussion, and whether the lecture technique is better suited to classes of older students than, for example, are group project techniques. Other questions which need to be probed include: What and how much visual aids material will be of value in the instruction of people whose visual and auditory acuity is diminishing? Do special materials need to be prepared? What type of leader is best suited for instructing older people, that is, how important are age and prestige factors in speakers?

Some progress in the development of materials has been made. There are at least three documentary filmsSteps of Age, ${ }^{8}$ Life with Grandpa, ${ }^{9}$ and Date of Birth ${ }^{10}$-which are valuable for discussion purposes. Lectures on problems of aging have been recorded by national experts and are available with instructional aids for use by educational groups, clubs, industry, and others. ${ }^{11}$ A manual for a course on retirement has been prepared by the $\mathrm{Bu}$ reau of Adult Education of the New York State Education Department. ${ }^{12}$

In addition to the usual classroom techniques of lecture and discussion, radio and television have been employed

8 International Film Bureau, 6 North Michigan Avenue, Chicago 2, Illinois.

${ }^{9}$ Same address.

10 National Film Board of Canada, 1270 Avenue of the Americas, New York 20, N. Y. 11 Audio-Visual Education Center, University of Michigan, Ann Arbor, Michigan.

12 "Retirement-A Second Career" (mimeographed), Bureau of Adult Education, New York State Education Department, Albany, N. Y., 1951. to educate older people and other age groups about the potentialities of the aging. ${ }^{13}$

\section{Financing education for older people}

After retirement, a large proportion of people must live on drastically reduced budgets. The fear of outliving their financial reserves leads to programs of severe economy, and hence to an avoidance of such expenditures as tuition for educational courses and materials.

It has been suggested that schools should offer free services to the aged, who have contributed to the building and maintenance of schools in their communities for many years. It has also been pointed out that school buildings and facilities normally receive far less than maximum use and can therefore be made available for use by adult groups at little added cost.

Certain types of programs can be operated with state or federal aid. Vocational education, for example, could be offered as part of the federally subsidized vocational educational program in agriculture, homemaking, trade and industrial education, and business occupations. The example of New York State has already been cited, in which funds are being made available for educational programs carried out by communities and industries, and for such services as counseling and retraining of older persons. Many other states have financial aid programs which provide reimbursement for each individual enrolled in an educational course. Unfortunately, under these programs educators have sometimes preferred to emphasize numbers enrolled, failing to consider the needs of minority groups such as represented by the aging.

13 Wilma Donahue, "Experiments in the Education of Older Adults," Adult Education, Vol. 2, December 1951. 


\section{Who shall do the educating?}

The problem of leadership in the education of the aging is complicated by the fact already observed that older adults are not usually found in large numbers in educational programs. They do constitute significant groups, however, in industry, community organizations, and churches. A national survey of educational programs has not been conducted, but casual observation would lead to the conclusion that more programs are offered under community and employment auspices than under the supervision of educational institutions. In a few instances educators have been invited to provide leadership for programs conducted under noneducational sponsorship.

Industry is not agreed as to the educator's responsibility in conducting programs for the older worker. According to one viewpoint, industry should assume entire responsibility for the education and pre-retirement conditioning of the older worker up to the point of retirement, after which the responsibility is transferred to the community. Other representatives of industry contend that educators should provide education for the aging worker either under the auspices of industry or by direct course offerings in the community. It is unlikely that educational programs which do not permit integration of industrial and community planning for the older worker will be maximally effective.

\section{Current Educational Programs}

Some of the representative programs offered by educational agencies, by community groups, and by industrial and business organizations will be reviewed in order to assess the present status of education for the aging and to deter- mine the respects in which its fourfold functions are being served.

\section{UNIVERSITIES AND COLIEGES}

\section{Adjustment programs}

In 1949 the New York State Joint Legislative Committee on Problems of the Aging conducted a survey of 468 American colleges, from which it was concluded that "our colleges are slowly but surely beginning to set up a wide variety of courses, institutes and research studies aimed at the ultimate goal of making man's later years his golden years." 14

Among those colleges offering courses directed toward the adjustment of the individual to the problems of aging are Syracuse University, the University of Illinois, the University of Chicago, and the University of Michigan. The most direct approach to individual diagnosis and counseling is to be found in an experimental course offered currently at the University of Chicago under the direction of the Committee on Human Development. The course is entitled "Making the Most of Maturity," and is designed to assist men and women between the ages of 55 and 64 in developing specific plans for their later years. In the weekly class meetings, extending over a period of approximately thirty weeks, information is being provided on gerontological problems on the basis of the needs of students, with emphasis and direction in the course content being determined by the class. Students are being aided in the formulation of individual plans for the retirement years by expert counseling in such areas as financial planning, vocational

14 October 28, 1949 release from the office of State Senator Thomas C. Desmond, Chairman, New York State Joint Legislative Committee on Problems of the Aging, Newburgh, New York. 
guidance, health, and personal and family problems. A medical examination including a diagnostic psychiatric interview is an integral part of the course. ${ }^{15}$

The programs in "Living in the Later Years" offered for older people through the Extension Service of the University of Michigan are based on the assumption that the individual older person who is equipped with essential information about aging and experienced in the skills necessary for adjustment to the problems of aging will be able to solve his own problems and adjust to age changes. $^{16}$ The casework approach of individualized counseling for everyone is not feasible in terms of time and personnel; nor should it be necessary. Most people at younger ages maintain their emotional equilibrium through the satisfactory execution of purposeful life tasks for which they have been trained. We consider this to be mature living. There is no reason to assume that old people have any less capacity for mature behavior.

The Michigan courses have taken difference forms, but all have been based on the achievement of adjustment by a group procedure. One course is currently underway in which the first part of a three-hour weekly period is used for instruction in the discussion of common gerontological problems and then followed by laboratory practice in social living. ${ }^{17}$ In another course, students defined some of the major problems with which they were concerned and set up projects for exploring them.

15 Mary H. Little, "Method and Content of an Intensive Course in Preparation for Later Maturity," paper read at Second International Gerontological Congress, St. Louis, September 1951.

${ }^{16}$ Clark Tibbitts, "Aging and Living," Adult Education Bulletin, Vol. 13 (1948), pp. 204-11.

17 Wilma Donahue, "Experiments in the Education of Older Adults," Adult Education, Vol. 2, December 1951.
The class divided into three groups; the projects selected by the groups and carried out during the semester were concerned with a study of the satisfactions and dissatisfactions of older people with the church, an analysis of work and training opportunities for older women in the local community, and planning a community center for older people. The students designed interview schedules, collected and analyzed data, and prepared final reports. In addition to gaining information, they learned about the community and the techniques to be used in approaching the problems of changing conditions for older people. ${ }^{18}$

In 1950, Dr. Henry Curtis, himself a man past eighty, proposed that colleges and universities establish a oneyear college to help older people learn how to adjust to the problems of old age. ${ }^{19}$ His proposal is based on the assumption that old age is a specific life period, and that people need training for living during this period just as for the earlier phases of life. The college which he proposes would have separate buildings, a campus, and its own staff. Its courses and training programs would be individualized and would be based on the results of a physical examination, appraisal of capacities, and financial resources for future living. Students would be taught the best daily habits regarding nutrition, exercise, play, and rest. They would also be stimulated and trained in the development of new interests, new fields of endeavor, new skills and creative activities.

The recently announced Sunk Mine Project, sponsored by the Walt Founda-

${ }^{18}$ Ibid.; see also Wilma Donahue, "Challenges of Aging," in Proceedings of the 1951 North Carolina Conference on Aging (in press).

10 Henry S. Curtis, "A College for Our Aging Population" (mimeographed), 1100 Hill Street, Ann Arbor, Michigan. 
tion, embodies much the same principle as Dr. Curtis' proposition. ${ }^{20}$ A college for over-sixty Vassar graduates and their husbands has been established at the Sunk Mine Farm, located twentyfive miles from Vassar College. The farm was provided by Mary Babbott Ladd, and the project will be directed by Mary Fisher Langmuir of the Vassar faculty. The educational plan is designed to meet the needs of older persons who are still physically fit, still adventurous in their attitude toward life, but in a quandary as to how to spend their presently enforced leisure. The opening month will be devoted to orientation courses in problems of readjustment, in world and national affairs, and in the arts and sciences, following which students may choose special interests for further study.

\section{Establishing attitudes}

Two methods have been employed by colleges and universities to bring the problems of an aging population before the public and to help change attitudes toward the aging. One method has been the sponsorship of radio and television programs which has already been mentioned. These programs have presented the older person with dignity and with emphasis on his positive qualities, in contrast to the semicaricature of old age characteristic of such commercial programs as "Life Begins at Eighty."

A second procedure used by colleges and universities in the education of the general public as well as professional groups has been the holding of conferences and institutes. Conferences have been held at the University of California, ${ }^{21}$ the University of Flor-

20 Mary Babbott Ladd, "The Sunk Mine Project," Vassar Alumnae Magazine, Vol. 37 (1951), pp. 20-21.

21 The Adjustment of the Aging Population, Berkeley: University Extension, University of California, 1949. ida, ${ }^{22}$ and the University of Chicago to explore research needs. General explorations of the problems of an aging population have been conducted in conferences at Marshall College, ${ }^{23}$ Ohio State University, Northwestern University, New York University, and the University of Michigan. ${ }^{24}$ Special topics have been considered by some conferences: geriatric nursing at the University of Minnesota; employment and social casework for the aged at the University of Wisconsin; and rehabilitation of the older worker at the University of Michigan.

\section{Training personnel}

In 1947 the results of a survey by the Division of Maturity and Old Age of the American Psychological Association showed that university and college instruction relating to problems of the older adult lagged behind the concern and needs of labor unions, social welfare groups, and the aging themselves. From the responses of seventyone medical schools only five were found to offer specific courses in geriatrics, and only two of sixty-two departments or colleges of education reported courses on the psychology of maturity. ${ }^{25}$

The situation has not improved significantly in the last five years. Everett Soop examined the 1949-50 catalogue

22 T. Lynn Smith, Ed., Problems of America's Aging Population, Gainesville: University of Florida Press, 1951.

23 Proceedings of Conference on Living the Later Years, Huntington, W. Va.: Marshall College, 1950.

${ }^{24}$ Proceedings published by University of Michigan Press, Ann Arbor, Michigan: Living Through the Older Years (Clark Tibbitts, Ed., 1949); Planning the Older Years (Wilma Donahue and Clark Tibbitts, Eds., 1950); Growing in the Older Years (Wilma Donahue and Clark Tibbitts, Eds., 1951).

${ }^{25}$ Dale B. Harris, "Courses of Instruction on Maturity and Old Age," Journal of Gerontology, Vol. 3 (1948), p. 225. 
of sixty schools of social work and found that only five listed special courses focused on the aging. ${ }^{26}$ In 1949 the New York State Joint Legislative Committee on Problems of the Aging found that out of 486 colleges and universities only 13 had special courses on some phase of aging. ${ }^{27}$ The same survey showed that some emphasis was placed on the aged in other courses in 463 schools, most frequently in departments of sociology or social work (234) and in economics (104). Since, 1949, a few more schools have instituted training courses. For example, New York University conducted a two-week workshop on gerontology as part of its adult education curriculum in the summer of $1951 .{ }^{28}$

\section{Research}

Every medical school in the United States is carrying out research on the diseases of old age. Other research areas, however, are receiving much less attention. The extent to which researches in the physical and medical sciences have outdistanced investigations in the psycho-social and economic spheres is indicated by the fact that more than three-fourths of the entries in Nathan Shock's Classified Bibliography on Gerontology and Geriatrics fall under the categories of "Biology of Aging," "Organ Systems," and "Geriatrics." The Committee on Human Development of the University of Chicago has taken leadership in the investigation of psycho-social problems of aging. The University of California,

${ }^{26}$ Everett J. Soop, "Proposed Programs in Education for an Aging Population," in Growing in the Older Years, cited note 24 supra, p. 138.

27 Unpublished report of New York State Joint Legislative Committee on Problems of the Aging, 94 Broadway, Newburgh, N. Y.

28 Wilma Donahue, unpublished report, 1510 Rackham Building, University of Michigan, Ann Arbor, Michigan.
Cornell University, and Columbia University are concerned with investigations on the employability of older people. As Shock points out, however, aging is not the major concern of any university research organizations, and most data have been accumulated by isolated investigators. ${ }^{29}$

\section{CITY SCHOOLS AND COLLEGES}

The public school system is the center of adult education in most communities. State aid programs make it possible for schools to receive remuneration for adult students in many states. Although there is no upper age limitation in such financial aid programs, few schools have emphasized education for the older adult.

Statistical data regarding the number and kinds of programs offered by the city schools are lacking. Homer Kempfer conducted a survey of schools in 1947 to determine the number offering courses for people past retirement age. ${ }^{30}$ $\mathrm{He}$ found that only seven schools were offering such courses; four offered training in handicrafts, one offered a course on nutrition, another a course on current events, and one school offered a course on family life.

The situation today is somewhat better than when the Kempfer survey was made. In Michigan alone, at least fifteen city school systems have provided general courses on the problems of aging. San Diego, California has a similar course. The Los Angeles city schools report the most ambitious program, with 1,600 individuals enrolled in sixteen different evening schools. These courses continue from October to June and are made up of a series of lectures devoted to each of the following

${ }^{29}$ Nathan W. Shock, Trends in Gerontology (Stanford Calif.: Stanford University Press, $1951)$, p. 75.

${ }^{30}$ Homer Kempfer, in a private communication to the author. 
topics: health, personal affairs, nutrition, psychology of aging, philosophy, and crafts. ${ }^{31}$

Henrietta Rabe of the New York State Bureau of Adult Education reports that in the past two years there has been a significant increase in the number of local adult education programs provided for older adults in New York. These have developed among special interest groups in clubs and in homes for the aged, and some of the activities are concerned with preparation for retirement, vocational counseling and retraining, and community education. ${ }^{32}$ In order to stimulate and encourage public schools to expand their programs for older adults, Mrs. Rabe has prepared a guide for a series of meetings designed to help the individual plan his retirement and find some secondary purpose in life. ${ }^{33}$

Direct attempts to change community attitudes have not been made in most of the school programs. Some programs, however, have featured community hobby shows and choruses which at least draw favorable attention to old people.

There appears to be little effort to design school programs so that they will yield research data, which are vitally needed for the guidance of other educators in developing programs.

\section{COMMUNITY EDUCATION PROGRAMS}

With the advent of compulsory retirement, communities have become aware of the problems of the increasing

31 Ann M. Barron, "A Large City School Program for Older Adults," Journal of Gerontology, Vol. 6 (1951), p. 58.

32 Henrietta F. Rabe, "Educational Programs for the Older Adult in New York State," paper read at Second International Gerontological Congress, St. Louis, September 1951.

33 "Retirement-A Second Career" (mimeographed), Bureau of Adult Education, New York State Education Department, Albany, N. Y., 1951. numbers of idle citizens. Concern for their welfare and their inadequate preparation for old age has led many communities to undertake educational programs to assist in adjustment to the problems of aging.

The educational programs developed by community agencies have varied from courses of lectures to institutes and conferences. A few examples will illustrate the variety of community agencies sponsoring programs: Young Men's Christian Association in Minneapolis ${ }^{34}$ and Hyde Park, Chicago; welfare councils in Dayton, ${ }^{35}$ Cleveland, New York City, Chicago, Rochester, Philadelphia, and Denver; libraries in Cleveland and Detroit; churches in Toledo, Cleveland, Grand Rapids, and Pasadena; and special research agencies, such as Community Studies, Inc. in Kansas City, Missouri.

Significant research on the community level has been carried out by Community Studies, Inc., which has surveyed the needs of the aging in Kansas City and has conducted an evaluative study of one of the local homes for the aging. The Community Project for the Aged, a committee of the Welfare Council of Metropolitan Chicago, has made an exhaustive study of the needs of the aged in Chicago. The Family and Children's Service of Minneapolis is making a study of the effects of an activities program in boarding homes for the aged.

\section{PROGRAMS FOR THE OLDER WORKER}

Education for older workers may have several goals: (1) training and retraining for new jobs, necessitated by technological changes or by age changes; (2) training for continuation

${ }^{34}$ Jerry Kaplan, mimeographed report, Hennepin County Welfare Board, Minneapolis, Minnesota, 1951.

${ }^{35}$ Gordon W. Allen, "Dayton's Institute on Preparation for Retirement," College and University, January 1951, pp. 247-51. 
of employment after retirement from primary occupations; or (3) preparation for retirement from work. Not only the older worker, but unions, employers, and the community also have an interest in providing education which will increase security in old age and maintain the older individual's participation. Industry recognizes that preparation for retirement is important, but it is also becoming concerned with the corollary objective of keeping older men in the labor force, since the proportion of laborers in the normally preferred age groups is now declining. Organized labor is concerned not only with maintaining adequate pensions, but also with the right of the individual to continue in employment as long as he is able to work. Communities have responsibility for utilizing the skills and the wisdom of the older worker.

These various interests should develop integrated programs to serve the needs of the older workers. Arthur Carstens points out that this will involve "training and retraining facilities, an adequate placement service, educational opportunities and all kinds of professional service," and he comments that "while active experimentation has begun, no comprehensive program for the older worker is underway anywhere in the United States." ${ }^{38}$ Perhaps it will be possible to correlate the isolated programs being carried out by industry, unions, and the community so that the older worker will not continue to experience such a marked contrast between his pre-retirement life and that which follows.

Most industrial programs at the present time are concerned solely with preparation of workers for retirement, and these programs are of several types. Some consist of a series of lectures pre-

\footnotetext{
36 Arthur Carstens, "Community Attitudes Toward the Aging," Adult Education, Vol. 1 (1950), p. 53.
}

sented either by professional educators, as in the General Motors of Canada experiment, ${ }^{37}$ or by personnel officers, as in the Standard Oil of New Jersey program. The programs of the Prudential Insurance Company of America and the Ford Motor Company are examples of those which provide personal counseling services. In other programs, printed literature on problems of the aging is issued, for example, the series "My Time-Is My Time" published by General Motors.

Research on employment and retirement practices is underway. Probably the most comprehensive is that being directed by Elizabeth Breckinridge of the University of Chicago's Committee on Human Development. It is from such studies as these that hope for integrated programs to serve the aging is to be found. As research reports are published, educators should study them with a view to determining what contributions can be made by educational programs toward maintaining the older individual as a participating and useful member of society.

\section{Conclusion}

It appears obvious that adult education has given but scant attention to the needs of older adults. Growing awareness of the problems and of the opportunity to assist in maintaining older people in functional roles is apparent, but little more than sporadic and isolated action will be taken by educators until more systematic information and more trained leadership are available.

In appreciation of this need, the Adult Education Association of the United States has adopted a recommendation that a study group be established to survey the educational needs of older

37 R. B. Robson, "Experiments in Education of the Older Worker," Industrial Medicine and Surgery, Vol. 18 (1949), pp. 365-67. 
adults, to provide direction and content for programs, and to develop plans for the integration of educational programs with total community planning for the older adult. A second recommendation adopted by the association was that a workshop for the training of leaders in the education of older people be conducted for the purpose of assessing needs, developing programs, and evaluating outcomes over a period of years.

The tempo of developments in the field of aging, however, precludes postponement of action until the results of such undertakings are available. Education for and about the aging must be developed at every level. Local communities can provide services to the individual older person; state organizations can assist in the formulation of policy and the promotion of co-operation between agencies; and national groups can provide for broad-scale research and for an over-all integration of activities for the aging. By these means, education can make its contribution to the maintenance of the older person as a useful member of society.

Wilma T. Donahue, Ph.D., Ani Arbor, Michigan, is research psychologist and chairman of the Division of Gerontology, Institute for Human Adjustment, and lecturer in psychology at the University of Michigan. She has served as director of the Bureau of Psychological Services, mental hygienist in the Student Health Service, and psychological counselor in the Veterans Service Bureau at the University of Michigan. She was chairman of the section on education of the National Conference on Aging, and is a member of the Michigan Governor's Commission for Study of the Problems of Aging and the Committee on Education for an Aging Population of the National Education Association. 